\title{
Three Silver(I) Coordination Polymers Based on Pyridyl Ligands and Auxiliary Carboxylic Ligands: Luminescence and Efficient Sensing Properties
}

\author{
Cong-Cong Chen,${ }^{\dagger}$ Yue Cai, ${ }^{\dagger}$ Long-Fei Wang, ${ }^{\dagger}$ Yun-Dang Wu,${ }^{\S}$ Hao-Jun Yin, ${ }^{\dagger}$ \\ Jia-Rong Zhou, ${ }^{\dagger}$ Chun-Lin Ni, ${ }^{*}, \dagger$ and Wei Liu ${ }^{*}, \dagger$ \\ $\dagger$ Key Laboratory for Biobased Materials and Energy of Ministry of Education, College of Materials \\ and Energy, South China Agricultural University, 483 Wushan Road, Guangzhou 510642, China \\ $\$$ Key Laboratory of Bioinorganic and Synthetic Chemistry of Ministry of Education, School of \\ Chemistry, Sun Yat-Sen University, Guangzhou 510275, P. R. China \\ $\S$ National-Regional Joint Engineering Research Center for Soil Pollution Control and Remediation in \\ South China, Guangdong Key Laboratory of Integrated Agro-environmental Pollution Control and \\ Management, Institute of Eco-environmental and Soil Sciences, Guangdong Academy of Sciences, \\ Guangzhou 510650, China
}


(a)

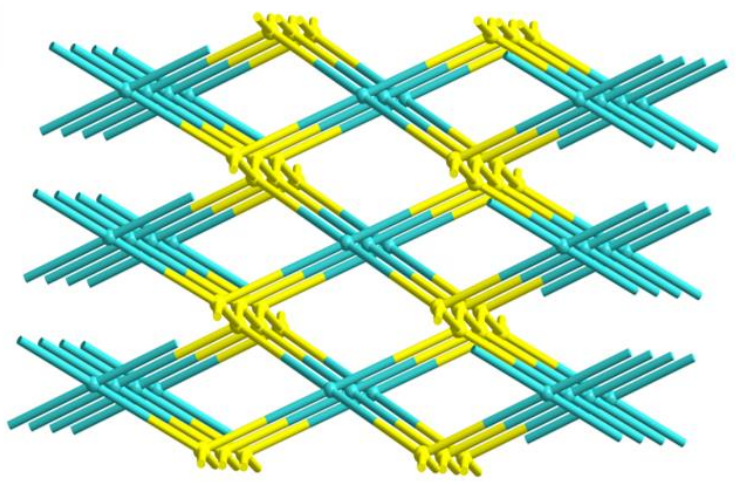

(b)

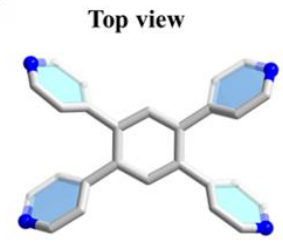

Side view

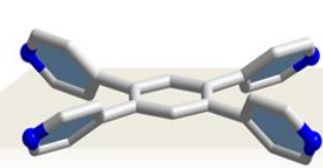

Figure S1. (a) Topological view of the bbf topology with Schläfli point symbol $\left\{6^{4} ; 8^{2}\right\}\left\{6^{6}\right\}_{2}$ for $\mathbf{1}$; (b) the conformations from diverse perspective of bztpy in $\mathbf{1}$. 

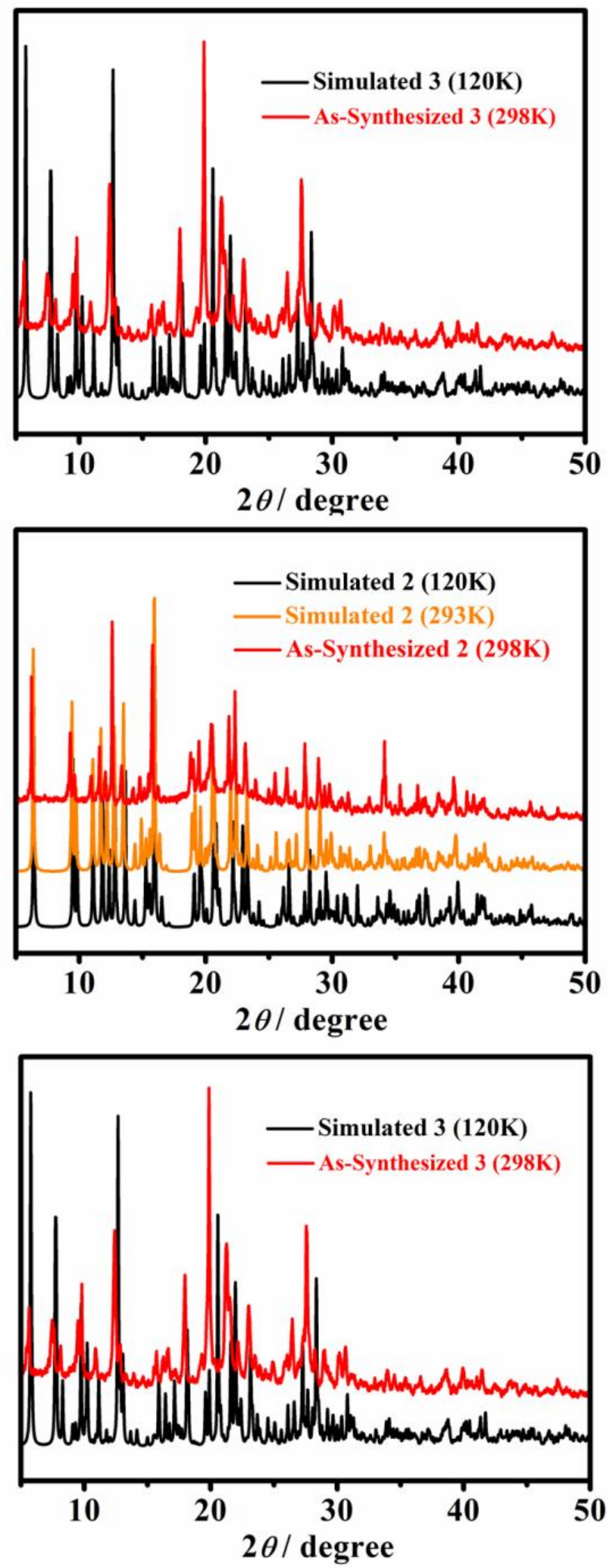

Figure S2. PXRD data as well as the simulated ones for compounds 1-3. 

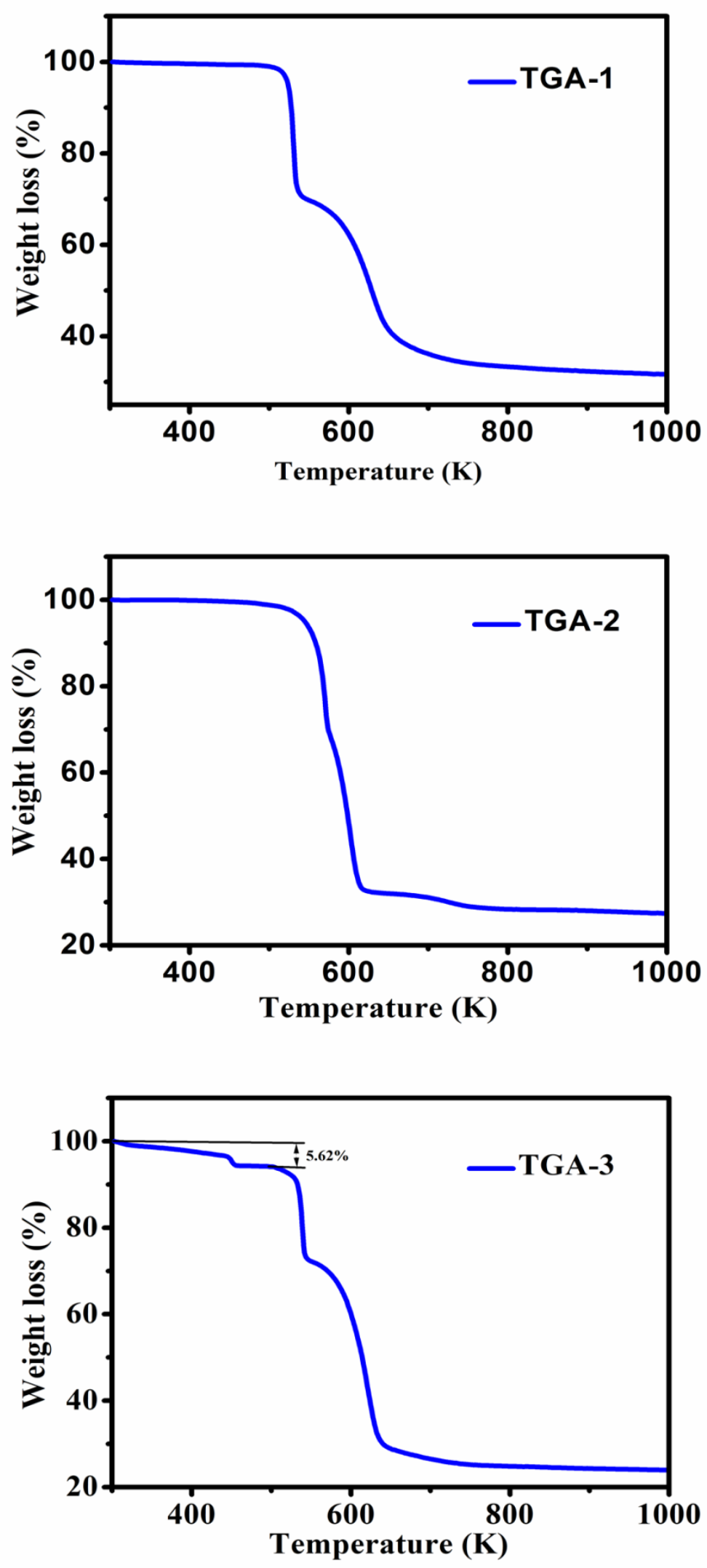

Figure S3. The TGA curves of compounds 1-3 under $\mathrm{N}_{2}$ environment. 


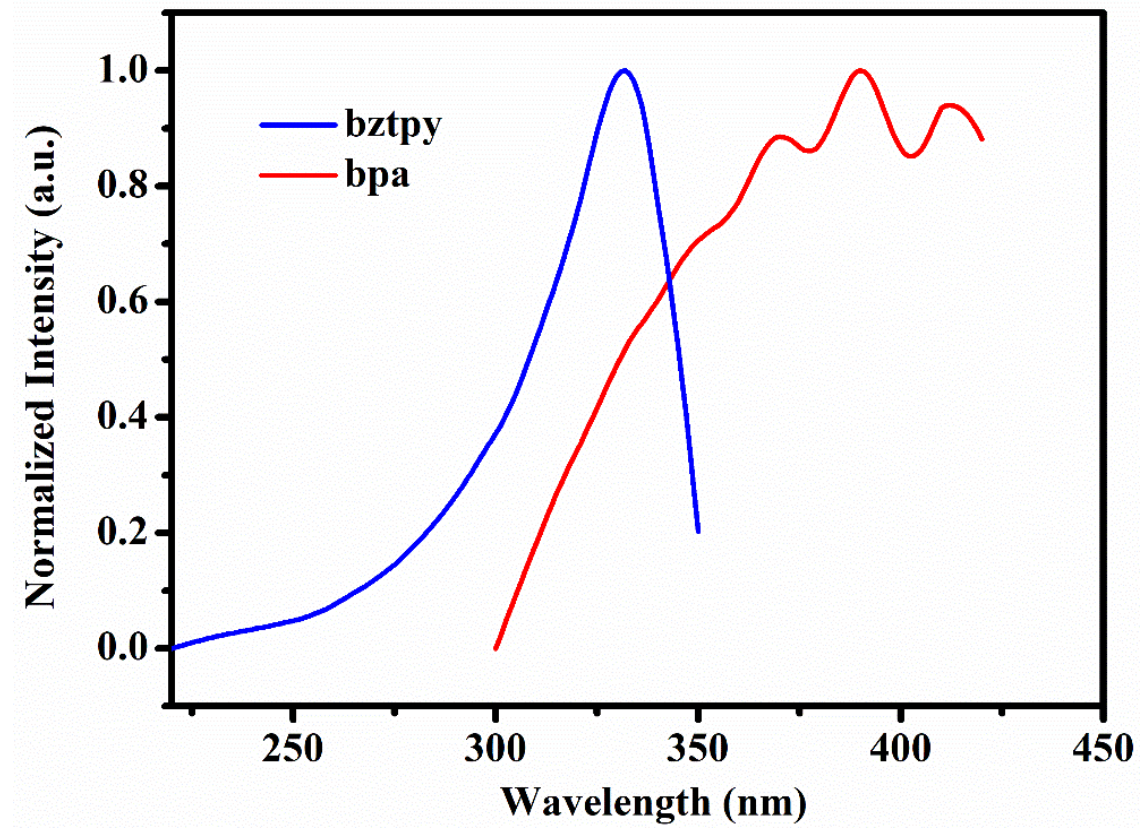

Figure S4. Solid-state luminescent excitation spectra of free ligand bztpy and bpa at room temperature.

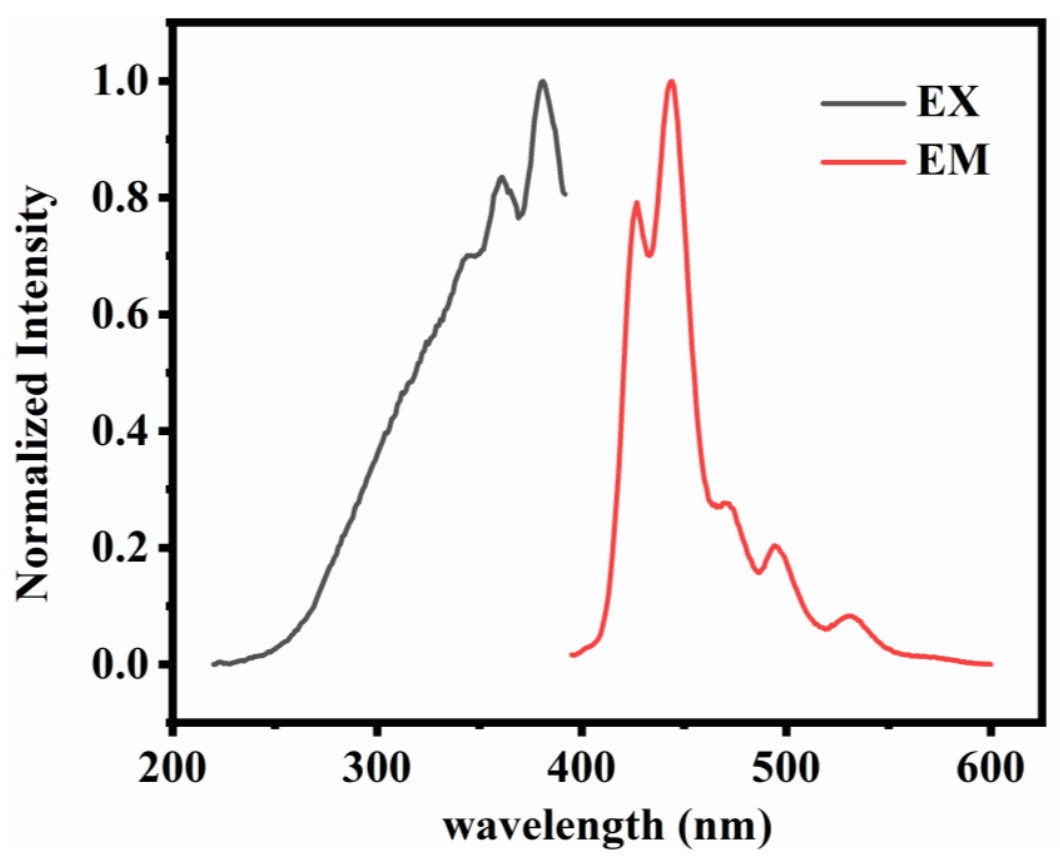

Figure S5. Solid-state luminescent emission and excitation spectra of anthracene at room temperature. 


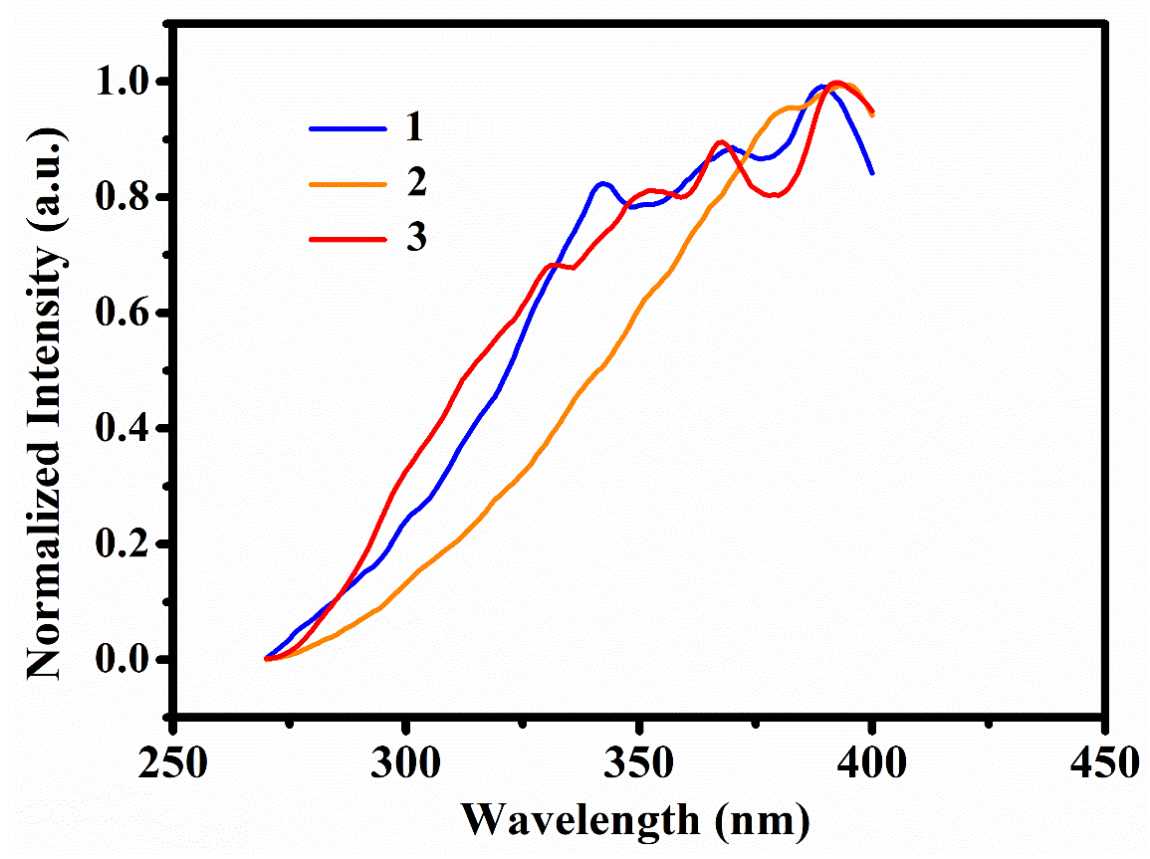

Figure S6. Solid-state luminescent excitation spectra of 1-3 at room temperature.

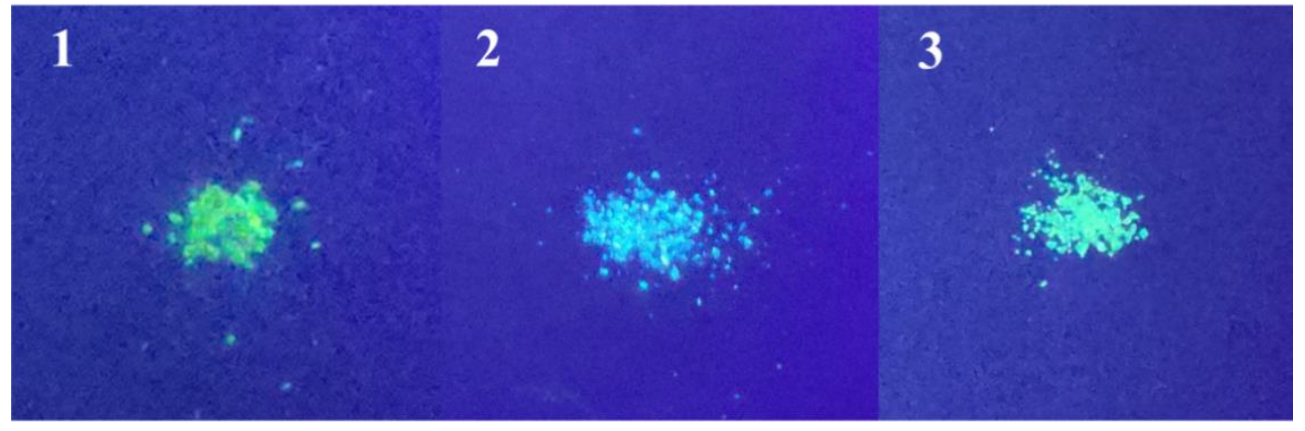

Figure S7. The observed luminescence of the crystals of compounds 1-3 irradiated with a standard laboratory UV lamp $\left(\lambda_{\mathrm{ex}}=365 \mathrm{~nm}\right)$, with CIE coordinates of $(0.192$, $0.327),(0.166,0.251)$ and $(0.197,0.391)$, respectively. 


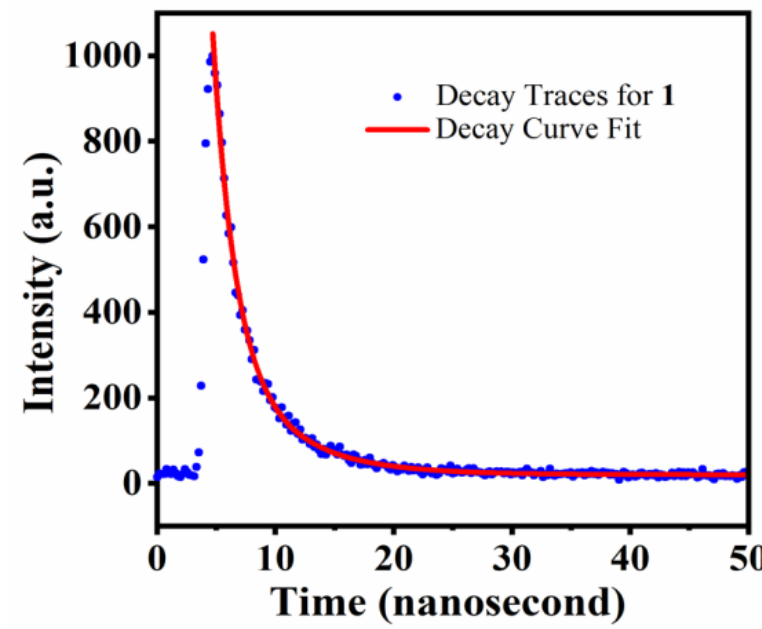

\begin{tabular}{|c|c|}
\hline Model & ExpDec2 \\
\hline Equation & $\begin{array}{c}\mathrm{y}=\mathrm{A} 1 * \exp (-\mathrm{x} / \mathrm{t} 1)+\mathrm{A} 2 * \exp ( \\
-\mathrm{x} / \mathrm{t} 2)+\mathrm{y} 0\end{array}$ \\
\hline $\mathrm{Plot}$ & $\mathrm{D}$ \\
\hline $\mathrm{y} 0$ & $20.28859 \pm 1.13824$ \\
$\mathrm{~A} 1$ & $9335.89131 \pm 752.68464$ \\
\hline $\mathrm{t} 1$ & $1.83948 \pm 0.09722$ \\
\hline $\mathrm{A} 2$ & $692.92118 \pm 161.04458$ \\
\hline $\mathrm{t} 2$ & $5.63048 \pm 0.50074$ \\
\hline Reduced Chi-Sqr & 105.08264 \\
\hline R-Square (COD) & 0.99627 \\
\hline Adj. R-Square & 0.99621 \\
\hline
\end{tabular}

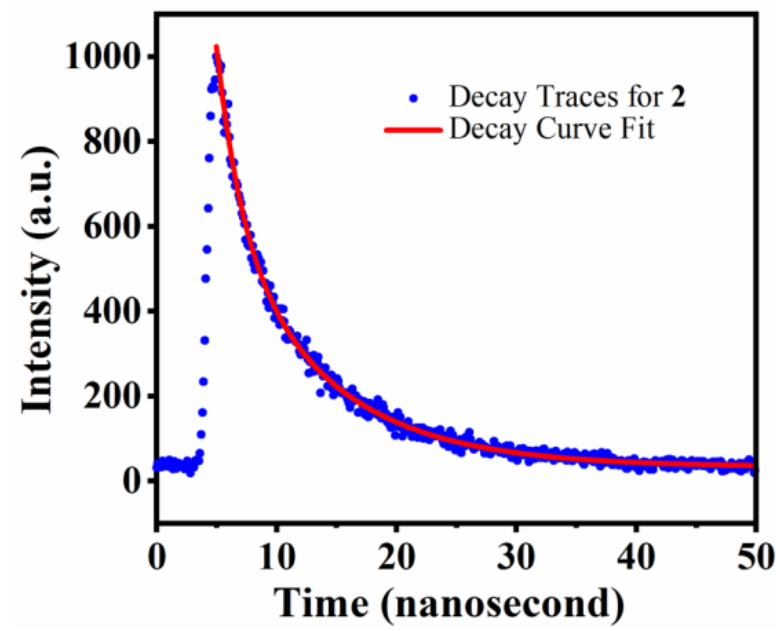

\begin{tabular}{|c|c|}
\hline Model & ExpDec2 \\
\hline Equation & $\begin{array}{c}\mathrm{y}=\mathrm{A} 1 * \exp (-\mathrm{x} / \mathrm{t} 1)+\mathrm{A} 2 * \exp \\
(-\mathrm{x} / \mathrm{t} 2)+\mathrm{y} 0\end{array}$ \\
\hline Plot & $\mathrm{D}$ \\
\hline $\mathrm{y} 0$ & $33.227 \pm 1.56501$ \\
\hline $\mathrm{A} 1$ & $4440.33098 \pm 474.49527$ \\
\hline $\mathrm{t} 1$ & $2.07624 \pm 0.12473$ \\
\hline $\mathrm{A} 2$ & $1038.57512 \pm 54.00707$ \\
\hline $\mathrm{t} 2$ & $8.74434 \pm 0.26144$ \\
\hline Reduced Chi-Sqr & 165.67166 \\
\hline R-Square (COD) & 0.99574 \\
\hline Adj. R-Square & 0.9957 \\
\hline
\end{tabular}

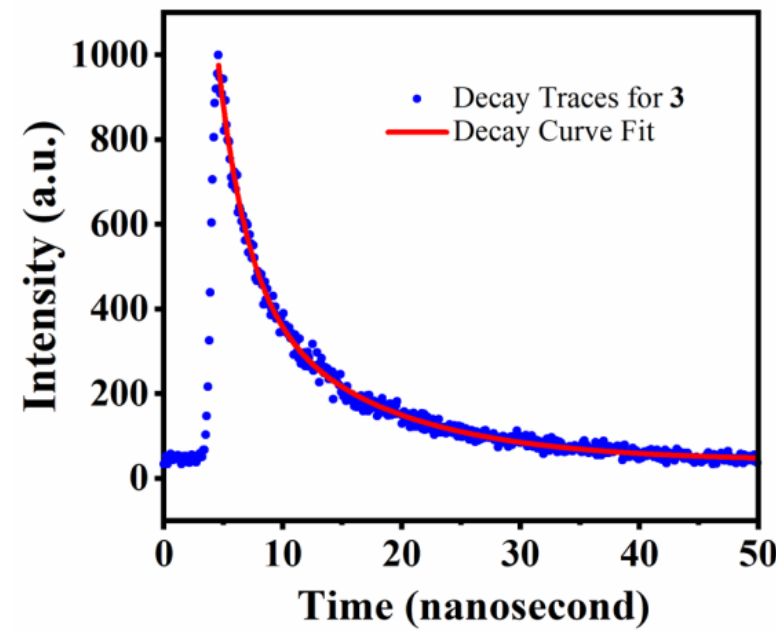

\begin{tabular}{|c|c|}
\hline Model & ExpDec2 \\
\hline Equation & $\begin{array}{c}\mathrm{y}=\mathrm{A} 1 * \exp (-\mathrm{x} / \mathrm{t} 1)+\mathrm{A} 2 * \exp \\
(-\mathrm{x} / \mathrm{t} 2)+\mathrm{y} 0\end{array}$ \\
\hline Plot & $\mathrm{D}$ \\
\hline $\mathrm{y} 0$ & $40.48729 \pm 2.47293$ \\
\hline $\mathrm{A} 1$ & $3430.81392 \pm 214.2034$ \\
\hline $\mathrm{t} 1$ & $2.41007 \pm 0.11136$ \\
\hline $\mathrm{A} 2$ & $636.46349 \pm 39.30111$ \\
\hline $\mathrm{t} 2$ & $11.31857 \pm 0.52784$ \\
\hline Reduced Chi-Sqr & 189.36814 \\
\hline R-Square (COD) & 0.99415 \\
\hline Adj. R-Square & 0.9941 \\
\hline
\end{tabular}

Figure S8. Emission decay curves of $\mathbf{1}$ (2.10 ns, top), 2 (3.34 ns, middle) and $\mathbf{3}$ (3.83 $\mathrm{ns}$, bottom), under the excitation of $445 \mathrm{~nm}(\mathbf{1}, \mathbf{3})$ and $360 \mathrm{~nm}(\mathbf{2})$. respectively. 

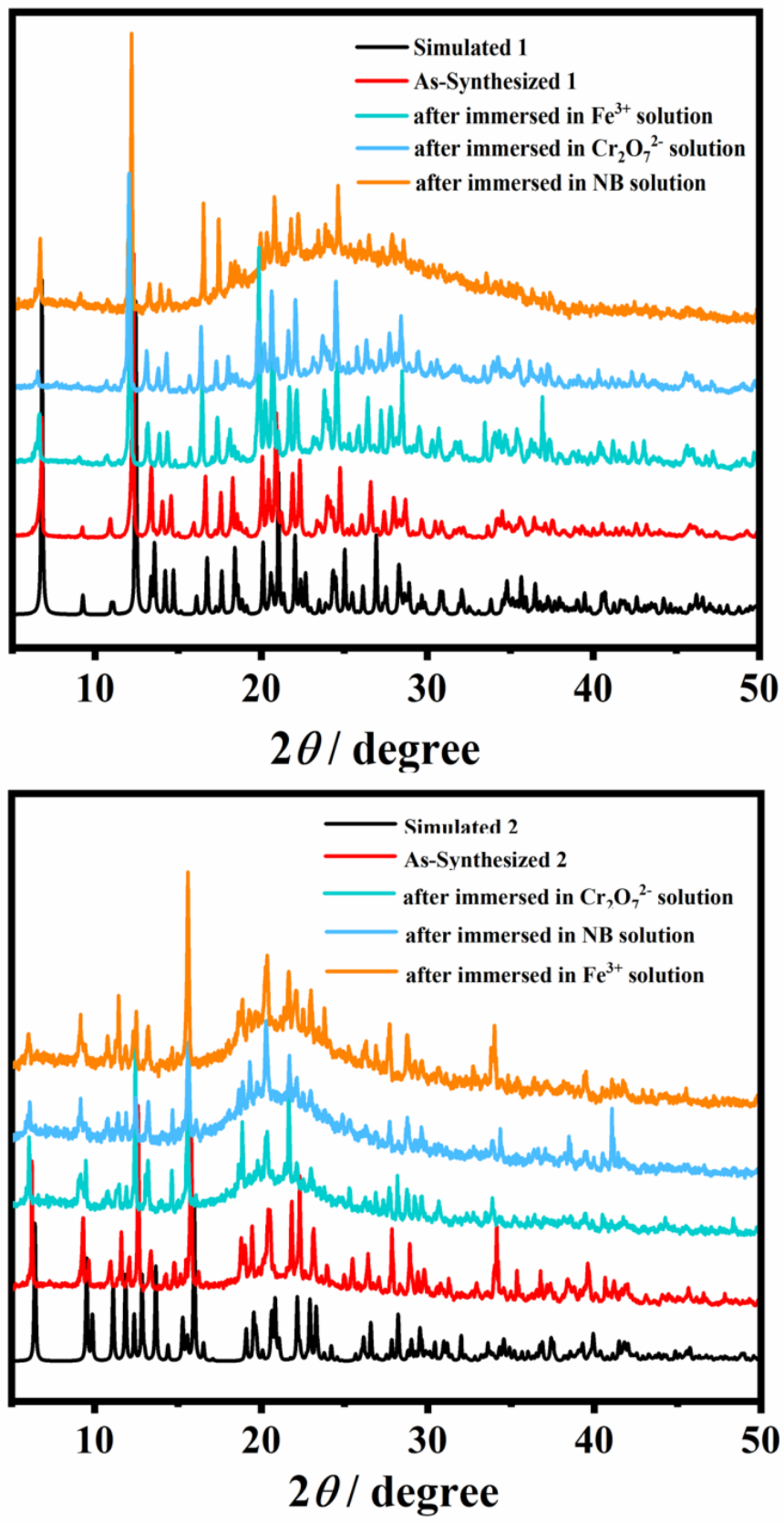

Figure S9. PXRD patterns of $\mathbf{1}$ and $\mathbf{2}$ after soaking in nitrobenzene, $\mathrm{Fe}^{3+}$ and $\mathrm{Cr}_{2} \mathrm{O}_{7}{ }^{2-}$ solutions. 
(a)

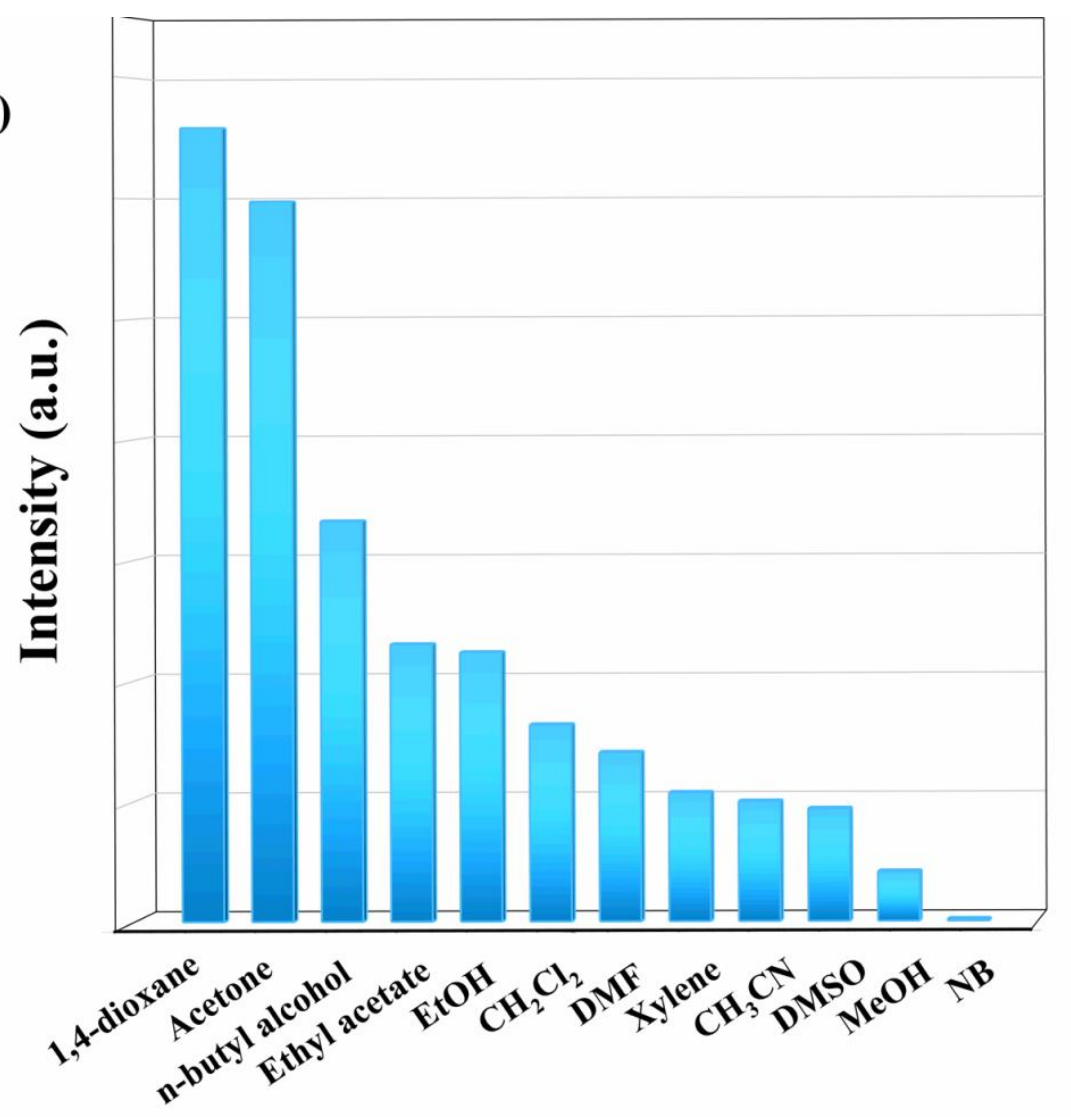

(b)

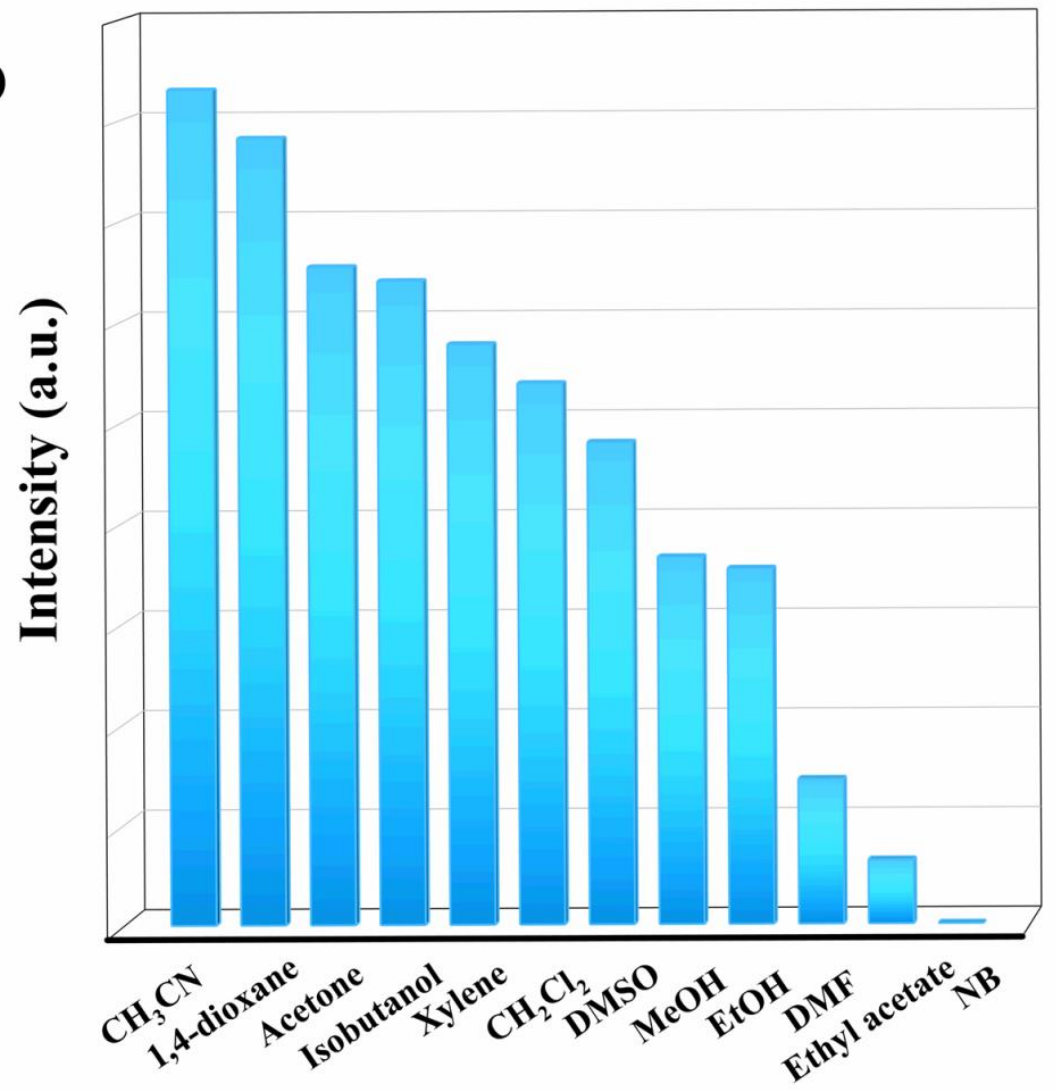

Figure S10. The luminescence intensities of the dispersed sample 1(a) and 2(b) in different organic solvents. 
(a)

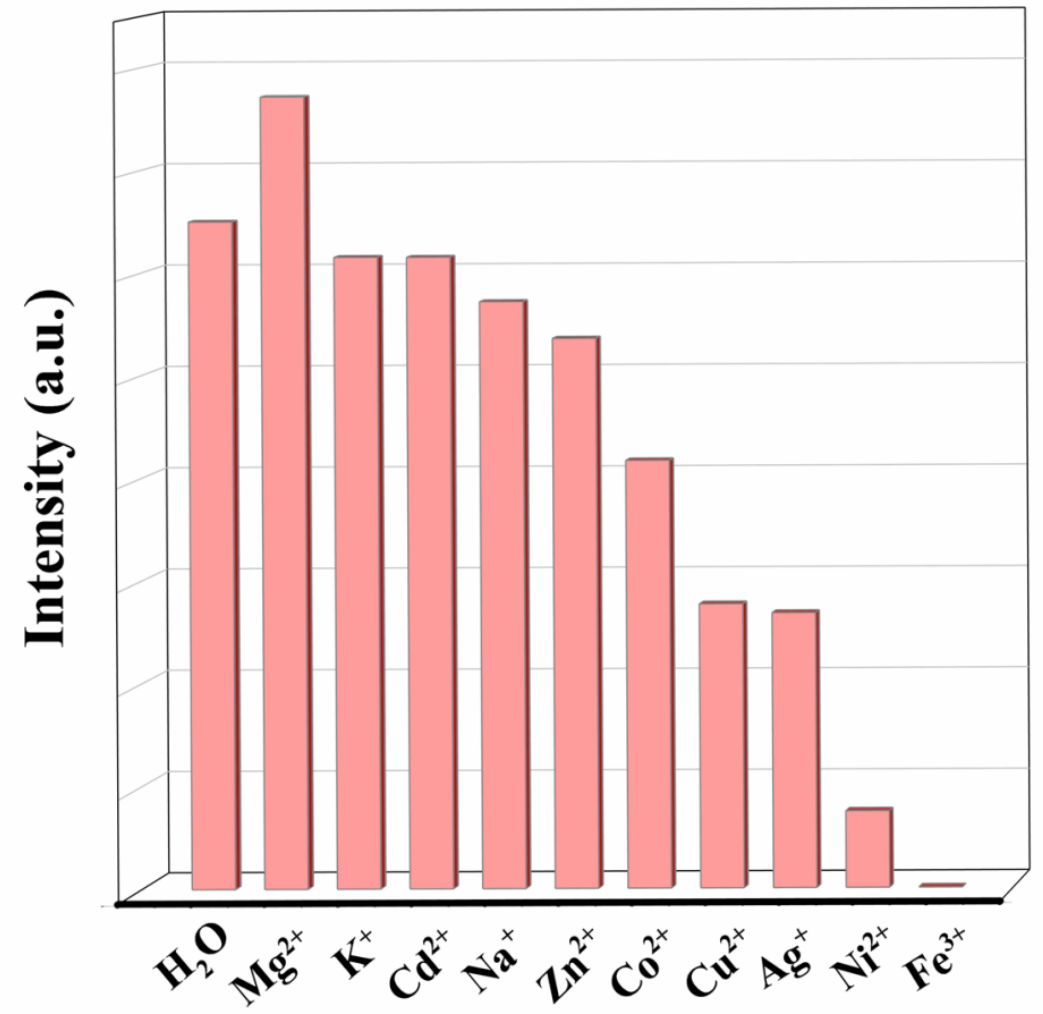

(b)

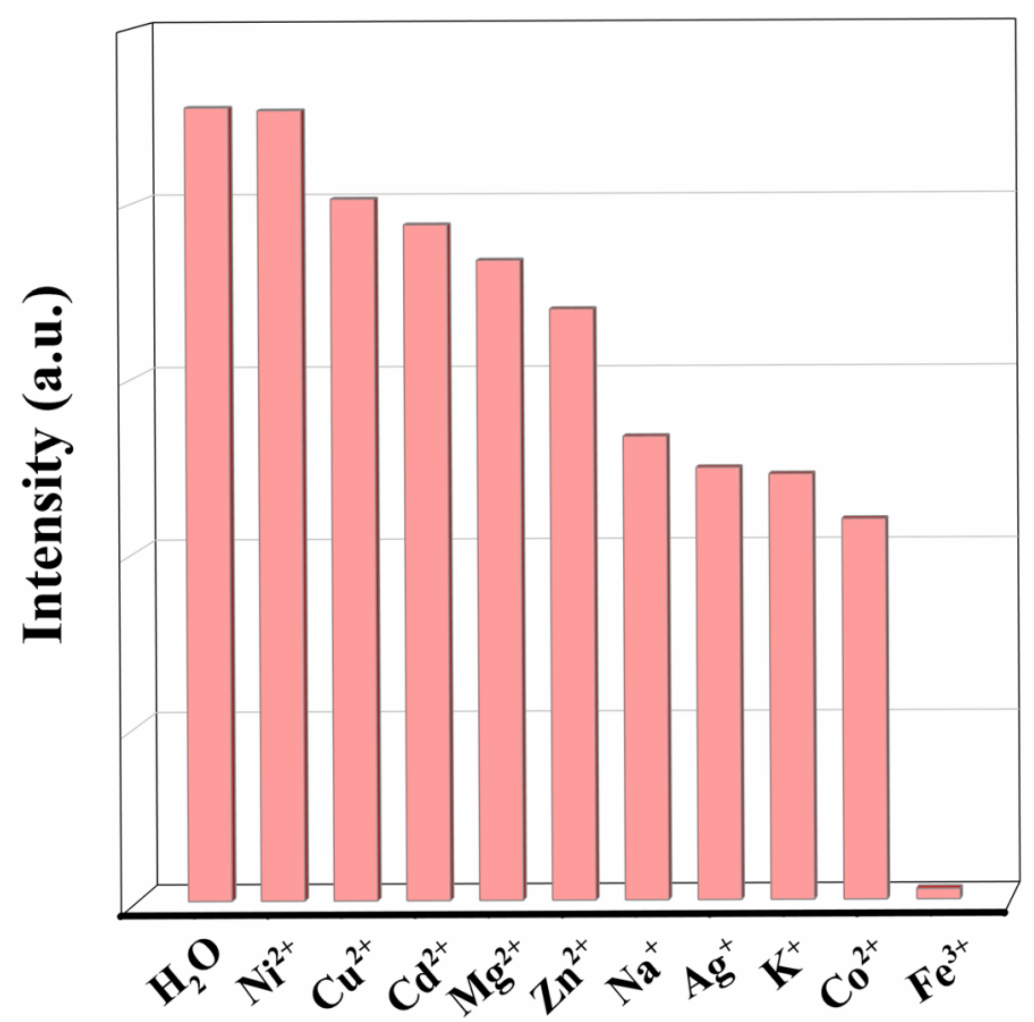

Figure S11. The luminescence intensities of the dispersed sample 1(a) and 2(b) in different metal ion solutions. 
(a)

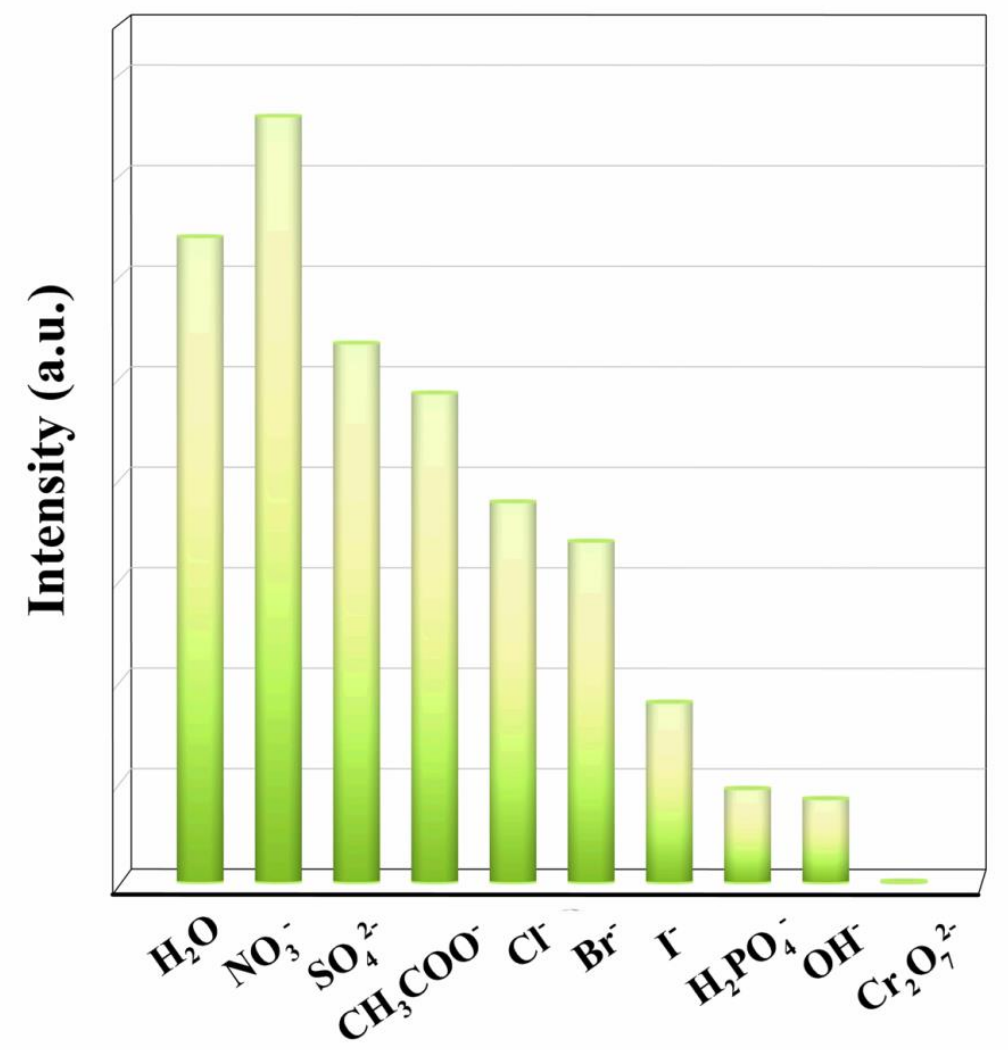

(b)

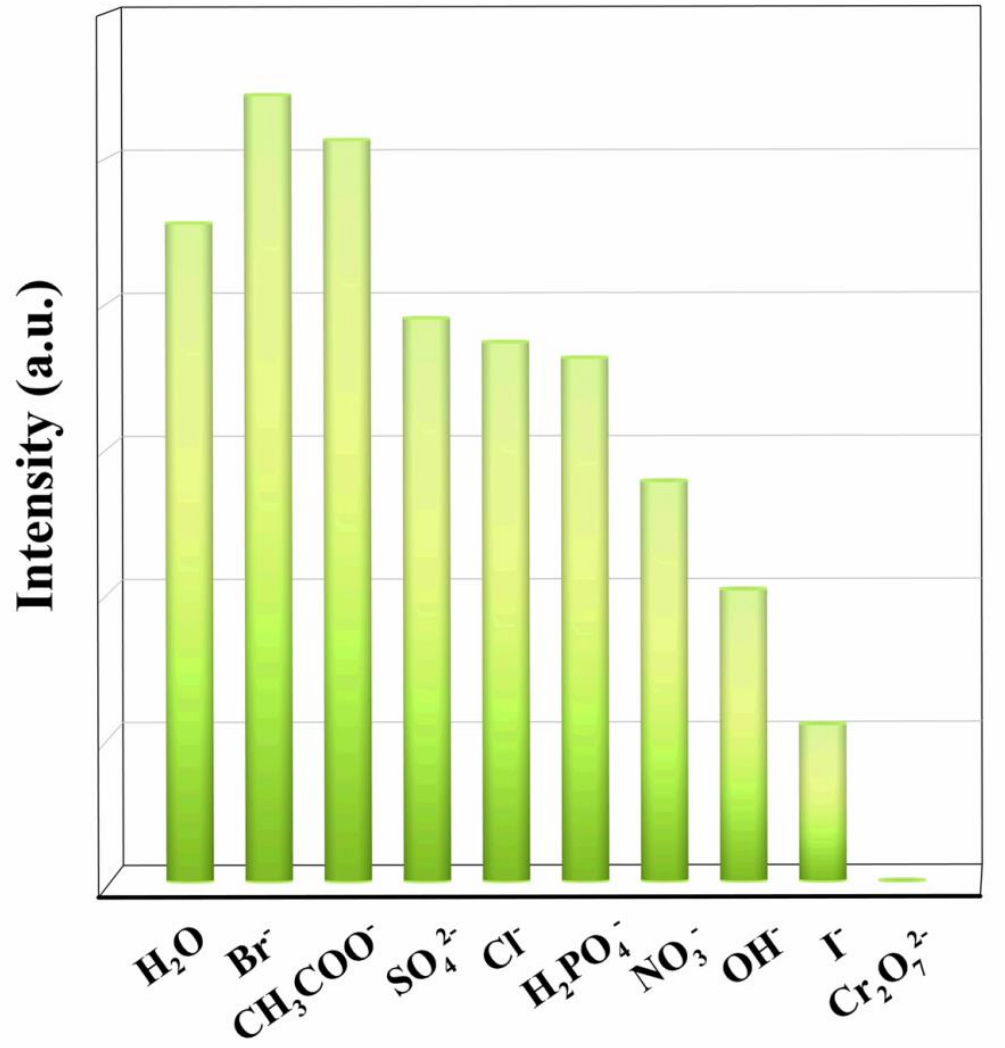

Figure S12. The luminescence intensities of the dispersed sample 1(a) and 2(b) in different anionic solutions. 
(a)

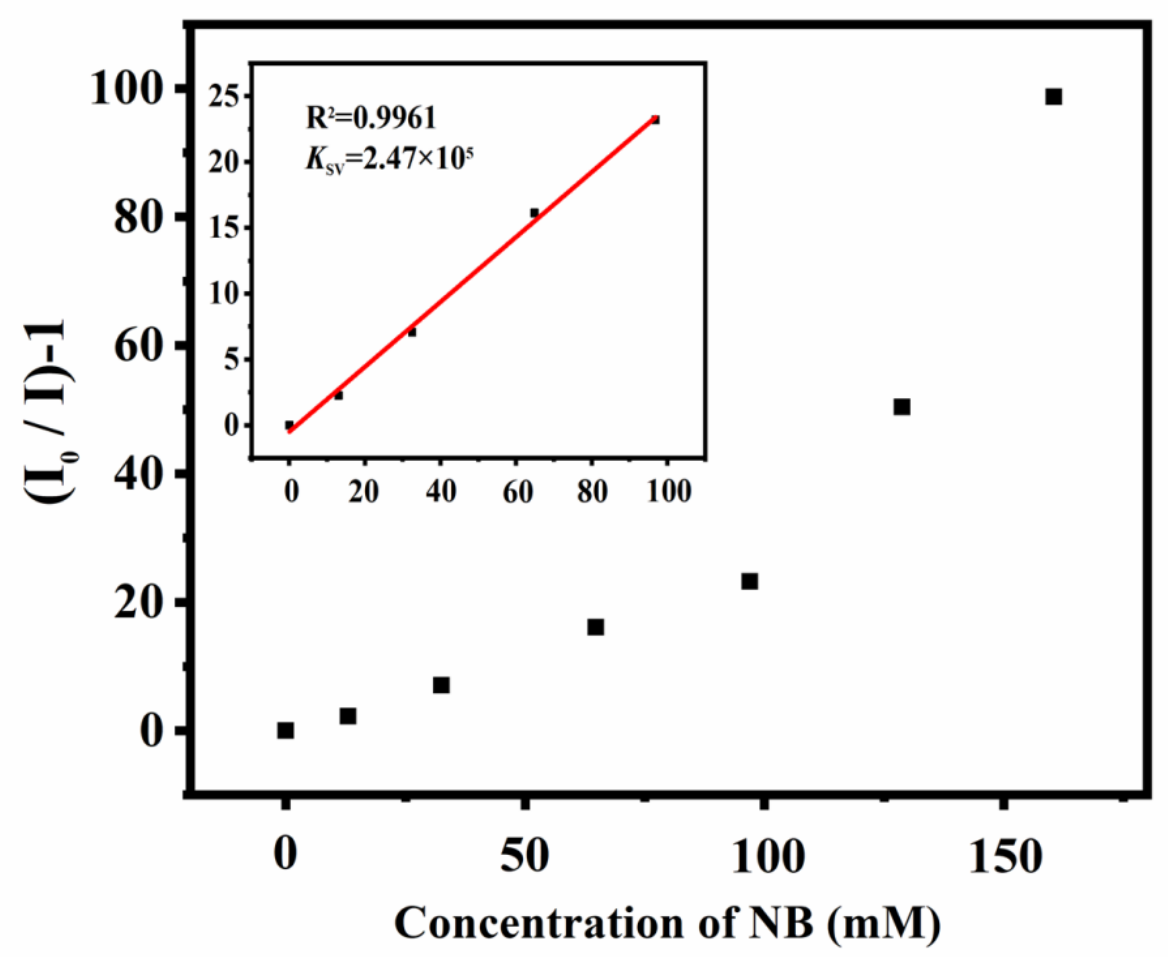

(b)

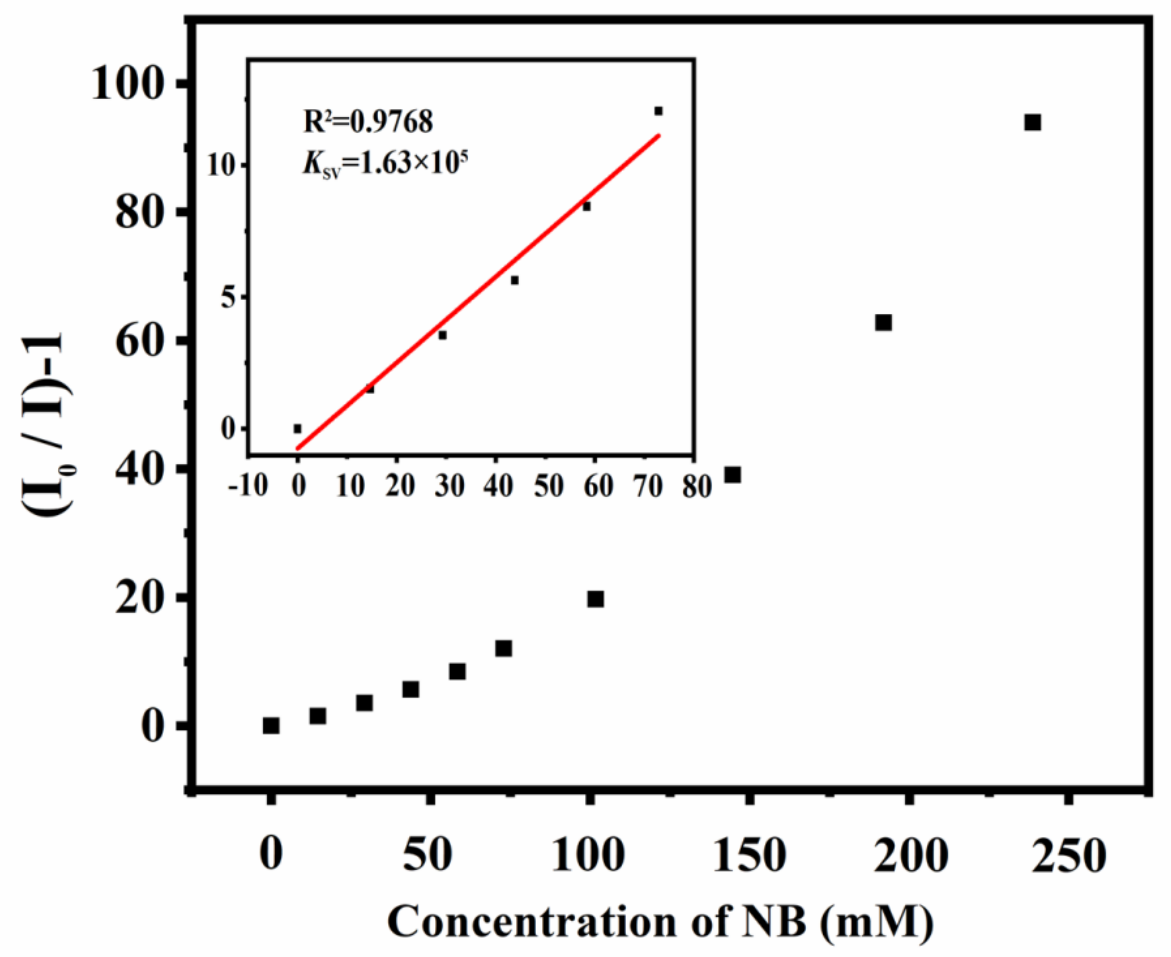

Figure S13. (a) The relationship between $\left[\mathrm{I}_{0} / \mathrm{I}-1\right]$ and concentration of NB for 1 . (b) The relationship between $\left[\mathrm{I}_{0} / \mathrm{I}-1\right]$ and concentration of NB for 2 . Insert: linear plot of $\left[\mathrm{I}_{0} / \mathrm{I}-1\right]$ at low concentration of NB. 
(a)

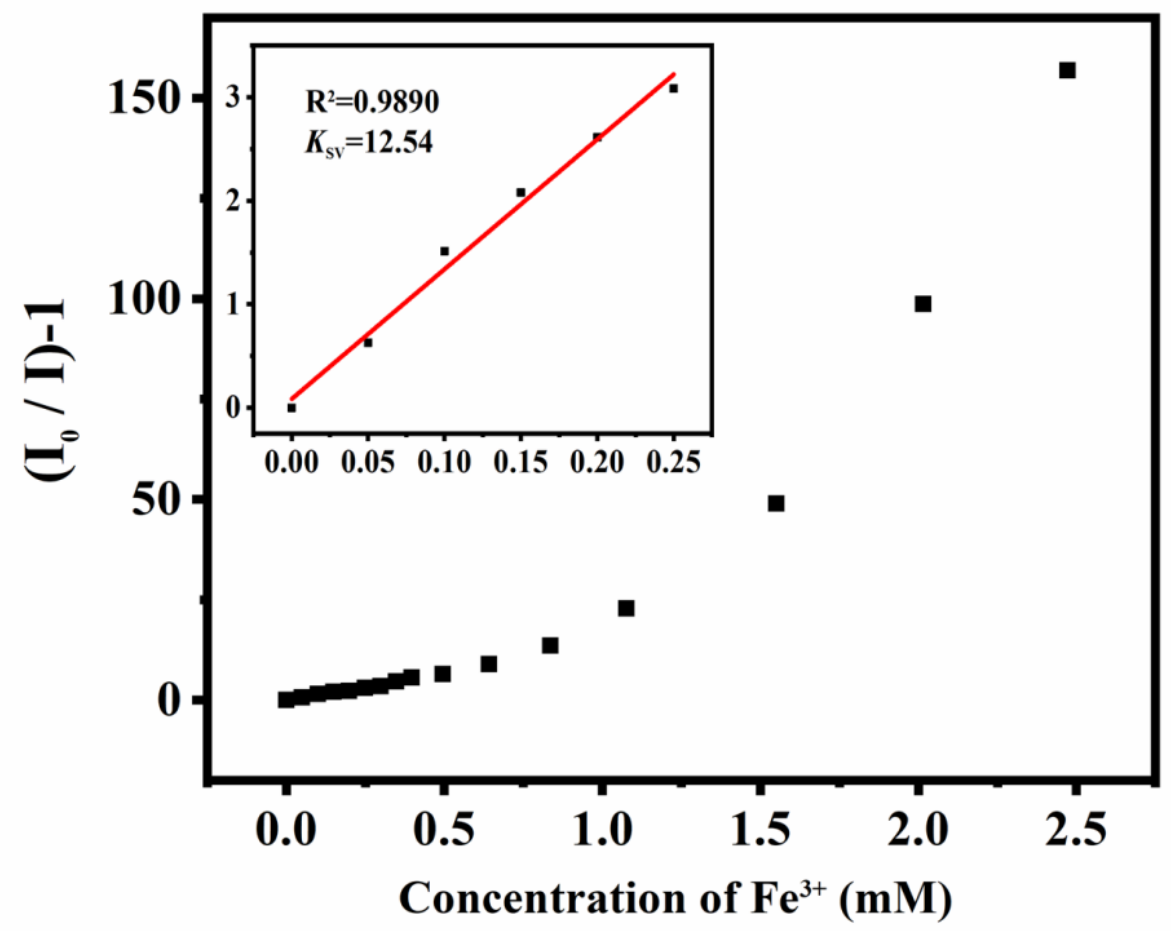

(b)

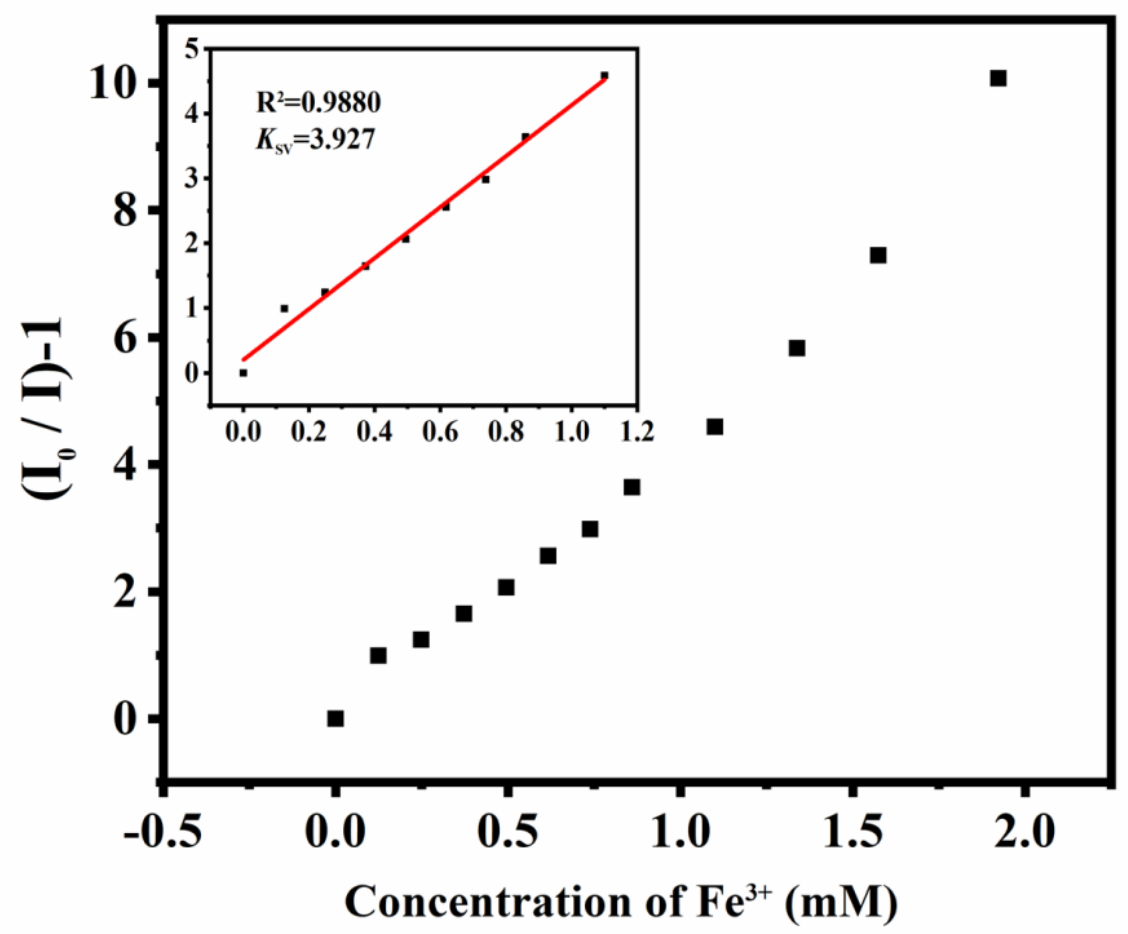

Figure S14. (a) The relationship between $\left[\mathrm{I}_{0} / \mathrm{I}-1\right]$ and concentration of $\mathrm{Fe}^{3+}$ for 1 . (b) The relationship between [ $\left.\mathrm{I}_{0} / \mathrm{I}-1\right]$ and concentration of $\mathrm{Fe}^{3+}$ for $\mathbf{2}$. Insert: linear plot of [I $/ \mathrm{I}-1]$ at low concentration of $\mathrm{Fe}^{3+}$. 
(a)

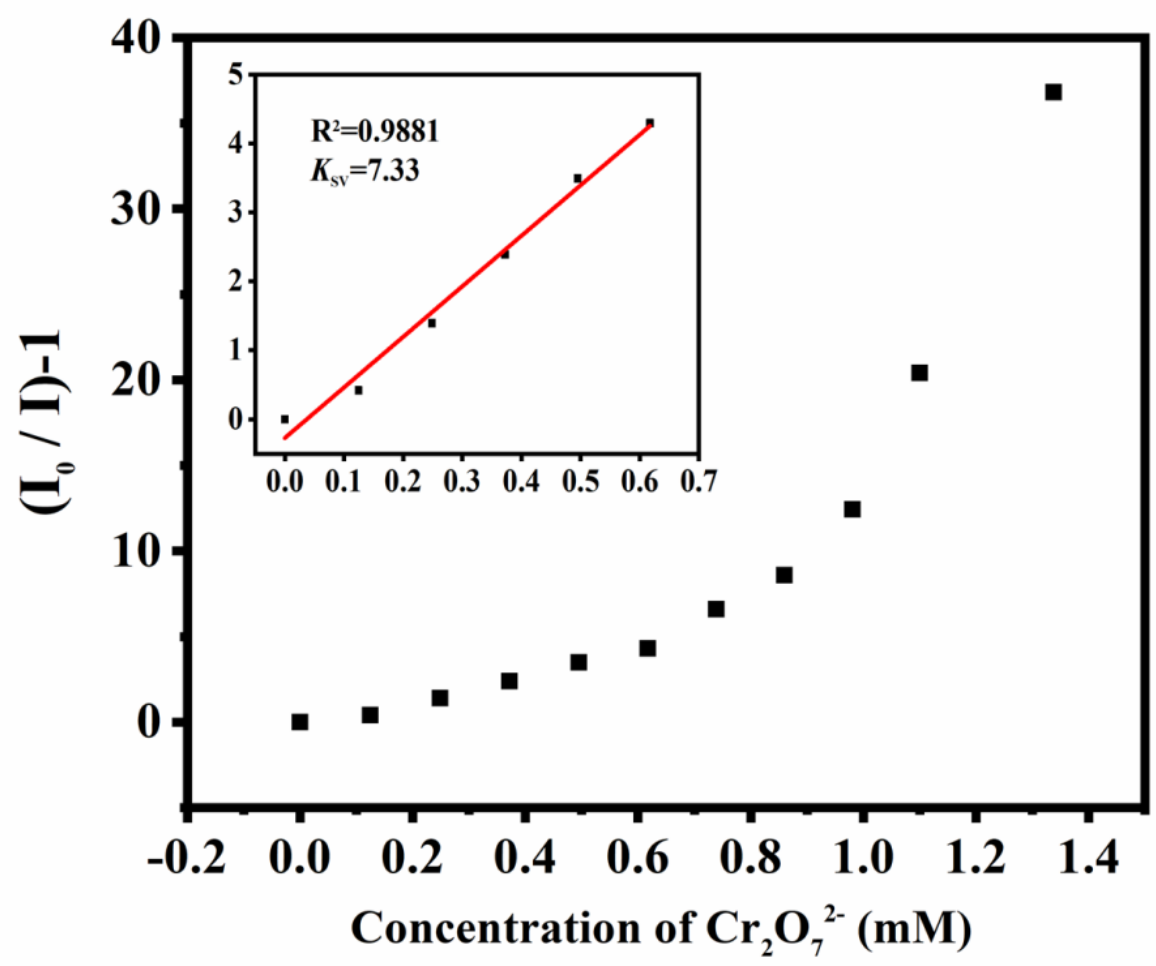

(b)

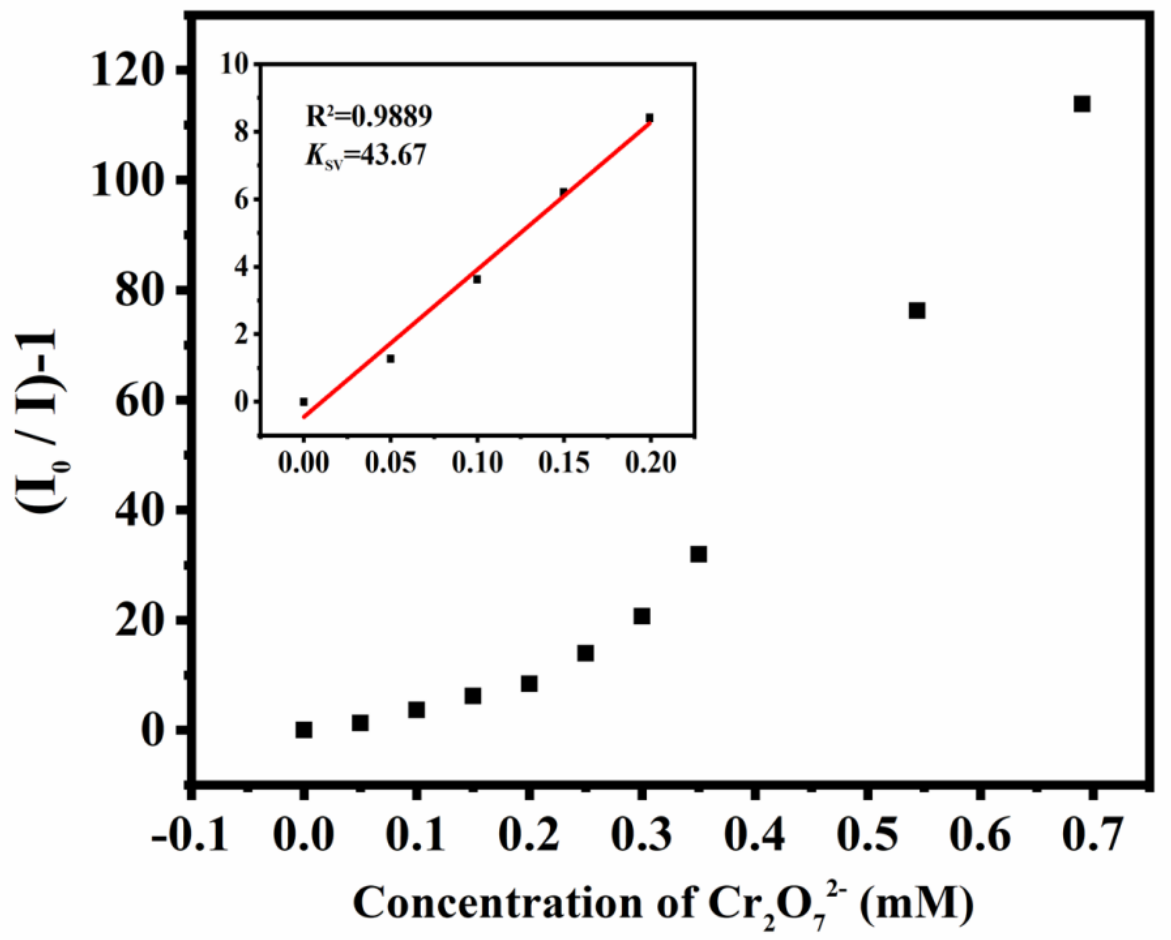

Figure S15. (a) The relationship between [I0/I-1] and concentration of $\mathrm{Cr}_{2} \mathrm{O}_{7}{ }^{2-}$ for $\mathbf{1}$. (b) The relationship between $[\mathrm{I} / \mathrm{I}-1-1]$ and concentration of $\mathrm{Cr}_{2} \mathrm{O}_{7}^{2-}$ for 2 . Insert: linear plot of $[\mathrm{I} / \mathrm{I}-\mathrm{I}-1]$ at low concentration of $\mathrm{Cr}_{2} \mathrm{O}_{7}^{2-}$. 

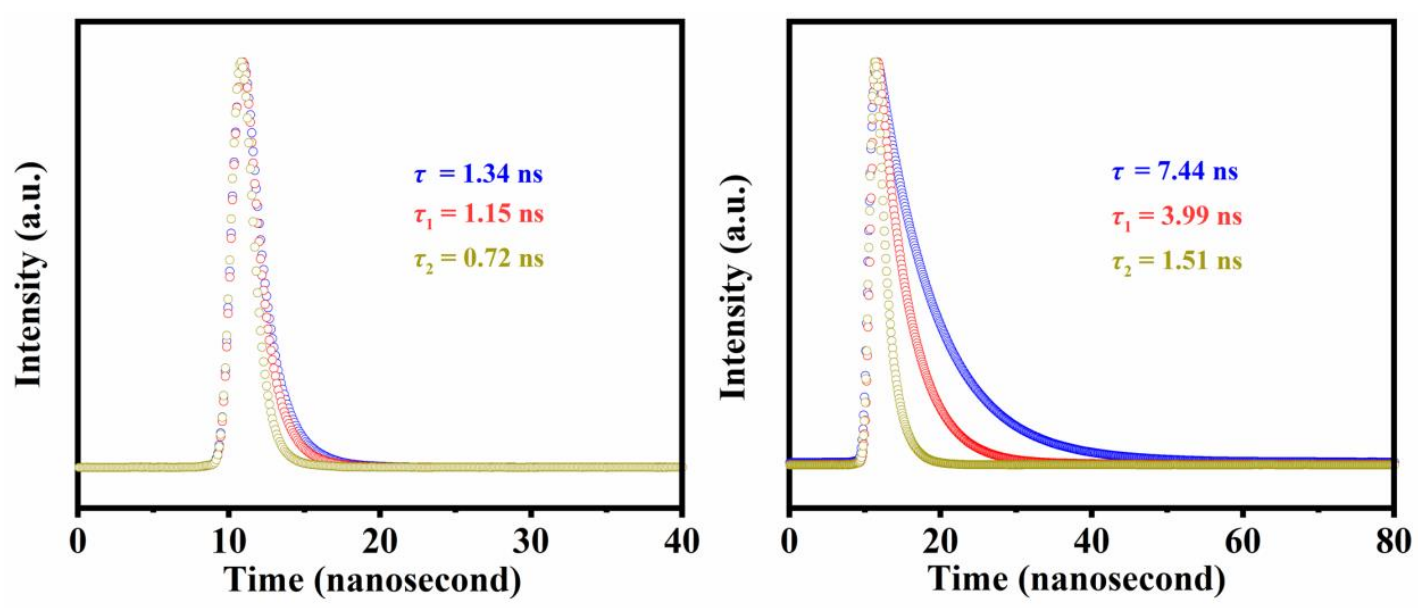

Figure S16. Time-resolved decay curves of 1 (left) in the absence (blue curve) and presence of $51.93 \mathrm{mM}$ (red curve) and $128.79 \mathrm{mM}$ (yellow curve) for NB; time-resolved decay curves of $\mathbf{2}$ (right) in the absence (blue curve) and presence of $72.86 \mathrm{mM}$ (red curve) and $238.73 \mathrm{mM}$ (yellow curve) for NB.
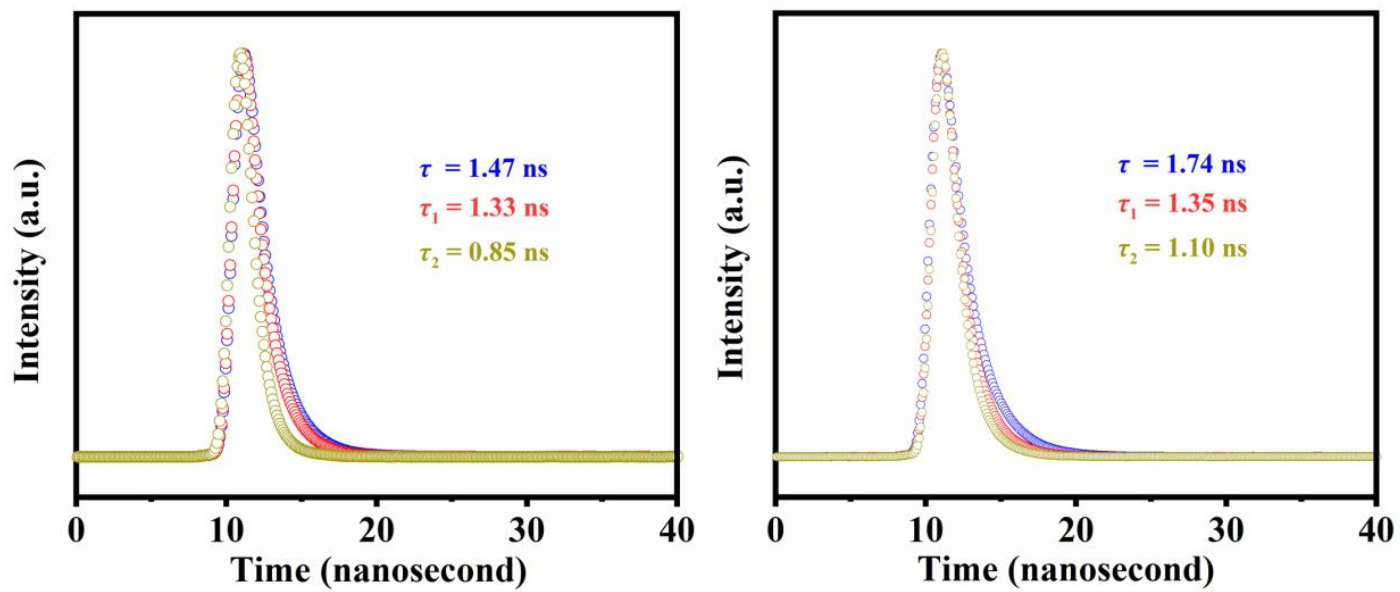

Figure S17. Time-resolved decay curves of 1 (left) in the absence (blue curve) and presence of $0.25 \mathrm{mM}$ (red curve) and $2.02 \mathrm{mM}$ (yellow curve) for $\mathrm{Fe}^{3+}$; time-resolved decay curves of 2 (right) in the absence (blue curve) and presence of $0.50 \mathrm{mM}$ (red curve) and $1.92 \mathrm{mM}$ (yellow curve) for $\mathrm{Fe}^{3+}$.
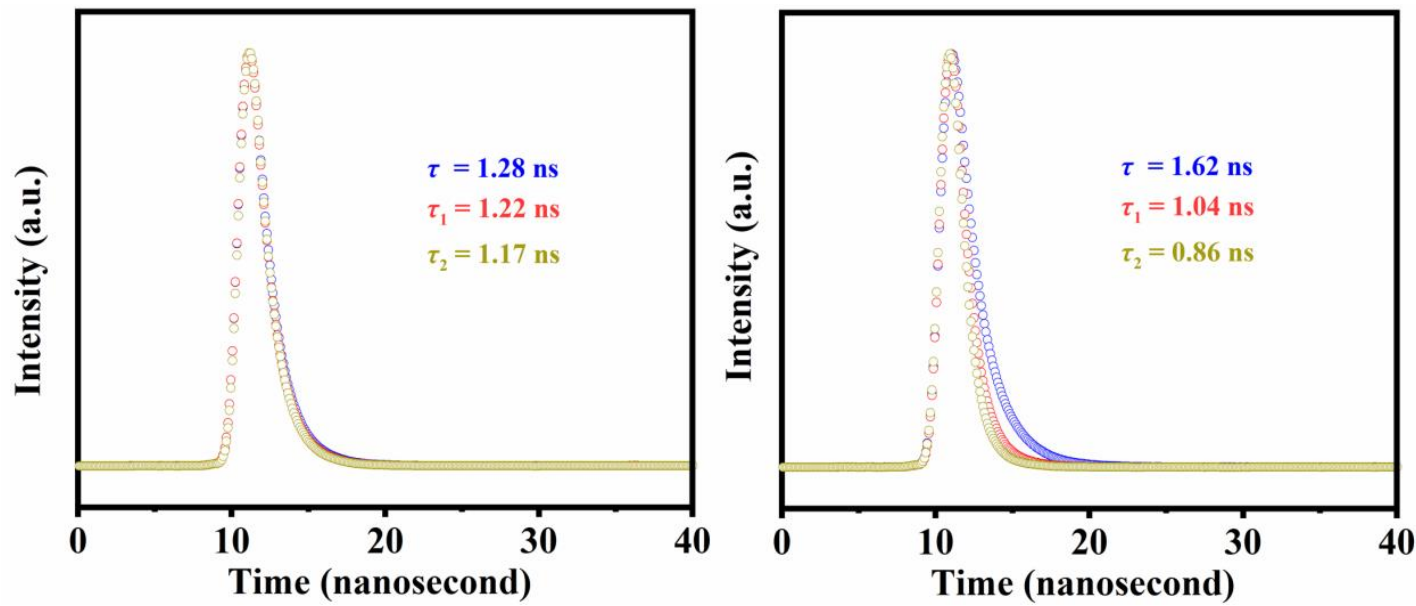
Figure S18. Time-resolved decay curves of 1 (left) in the absence (blue curve) and presence of $0.50 \mathrm{mM}$ (red curve) and $1.22 \mathrm{mM}$ (yellow curve) for $\mathrm{Cr}_{2} \mathrm{O}_{7}^{2-}$; time-resolved decay curves of 2 (right) in the absence (blue curve) and presence of $0.20 \mathrm{mM}$ (red curve) and $0.62 \mathrm{mM}$ (yellow curve) for $\mathrm{Cr}_{2} \mathrm{O}_{7}^{2-}$.
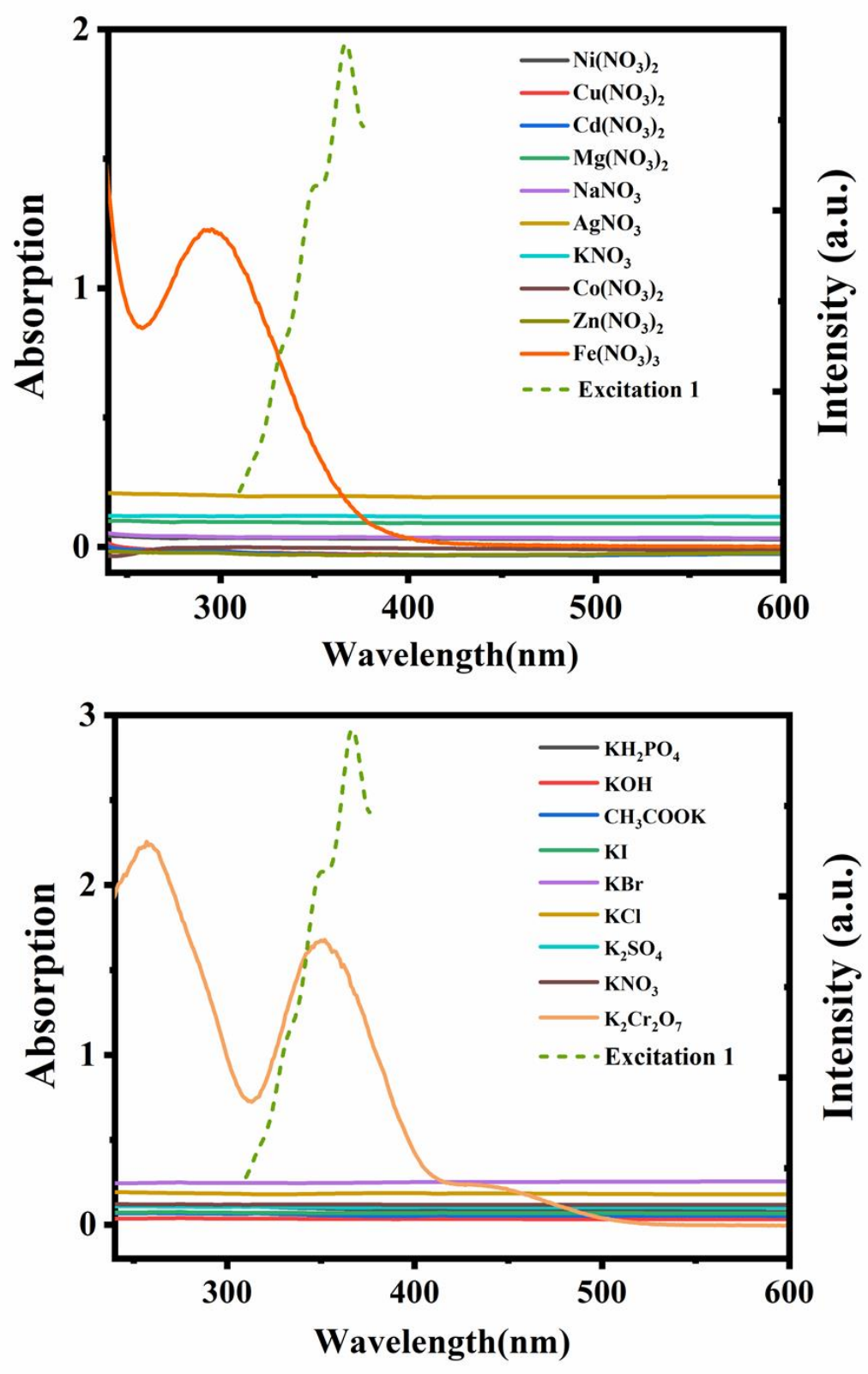

Figure S19. UV-Vis adsorption spectrum of $\mathrm{M}\left(\mathrm{NO}_{3}\right)_{n}$ aqueous solution (top) or $\mathrm{K}_{n}(\mathrm{~A})$ aqueous solution (bottom) with the same volume of $5 \times 10^{-4} \mathrm{~mol} \cdot \mathrm{L}^{-1}$ and the excitation spectrum of $\mathbf{1}$. 

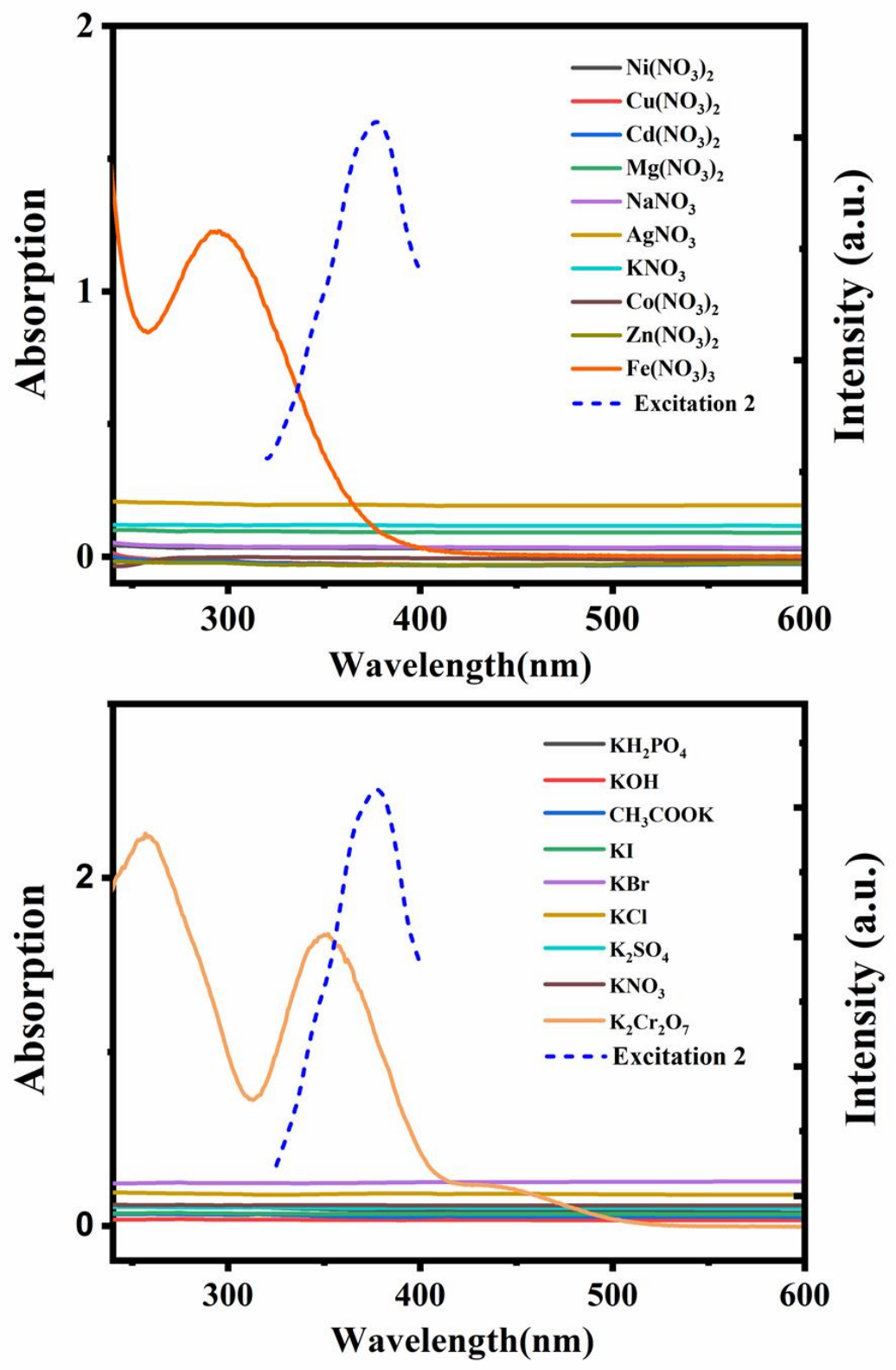

Figure S20. UV-Vis adsorption spectrum of $\mathrm{M}\left(\mathrm{NO}_{3}\right)_{n}$ aqueous solution (top) or $\mathrm{K}_{n}(\mathrm{~A})$ aqueous solution (bottom) with the same volume of $5 \times 10^{-4} \mathrm{~mol} \cdot \mathrm{L}^{-1}$ and the excitation spectrum of 2. 

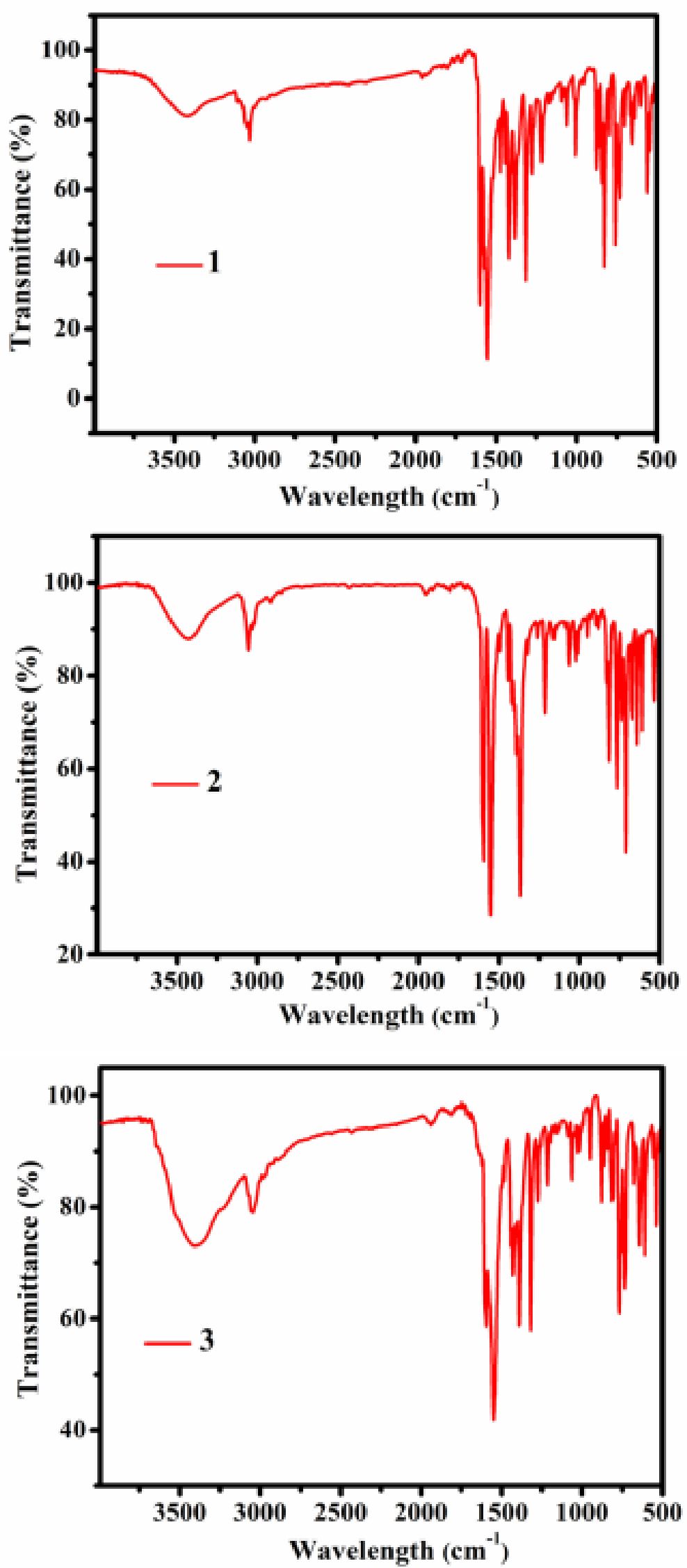

Figure S21. IR spectra of the as-synthesized 1-3. 
Table S1. Crystallographic data of 1-3.

\begin{tabular}{llll}
\hline Compound reference & $\mathbf{1}$ & $\mathbf{2}$ & $\mathbf{3}$ \\
\hline Chemical formula & $\mathrm{C}_{28} \mathrm{H}_{18} \mathrm{AgN}_{2} \mathrm{O}_{2}$ & $\mathrm{C}_{31} \mathrm{H}_{21} \mathrm{AgN}_{2} \mathrm{O}_{2}$ & $\mathrm{C}_{80} \mathrm{H}_{60} \mathrm{Ag}_{2} \mathrm{~N}_{4} \mathrm{O}_{7}$ \\
Formula Mass & 522.31 & 561.37 & 1405.06 \\
Temperature / K & 120 & 120 & 120 \\
Crystal system & monoclinic & triclinic & monoclinic \\
Space group & $P 2_{1} / c$ & $P-1$ & $P 21 / n$ \\
$a / \AA$ & $8.0085(3)$ & $9.0910(5)$ & $11.8223(4)$ \\
$b / \AA$ & $10.2550(4)$ & $9.3703(5)$ & $17.2565(6)$ \\
$c / \AA$ & $26.1272(9)$ & $13.9252(7)$ & $30.6670(10)$ \\
$\alpha /{ }^{\circ}$ & 90 & $85.240(2)$ & 90 \\
$\beta /{ }^{\circ}$ & $95.5300(10)$ & $82.832(2)$ & $95.4640(10)$ \\
$\gamma /{ }^{\circ}$ & 90 & $83.607(2)$ & 90 \\
$V / \AA^{3}$ & $2135.77(14)$ & $1166.76(11)$ & $6228.0(4)$ \\
$Z$ & 4 & 2 & 4 \\
$\mu($ Mo & & 0.897 & 0.693 \\
reflns collected & 0.973 & 29516 & 43967 \\
independent reflns & 15225 & 5819 & 14042 \\
$R_{\text {int }}$ & 4921 & 0.0416 & 0.0609 \\
$R_{I}{ }^{a}(I>2 \sigma(I))$ & 0.0341 & 0.0268 & 0.0456 \\
$w R_{2}{ }^{\mathrm{b}}($ all data $)$ & 0.0270 & 0.0554 & 0.0854 \\
$\mathrm{GOF}^{-1}$ & 0.0621 & 1.032 & 1.021 \\
\hline
\end{tabular}

${ }^{a} R_{1}=\Sigma|| F_{\mathrm{o}}|-| F_{\mathrm{c}}|| / \sum\left|F_{\mathrm{o}}\right|,{ }^{b} w R_{2}=\left[\sum w\left(F_{\mathrm{o}}{ }^{2}-F_{\mathrm{c}}{ }^{2}\right)^{2} / \sum w\left(F_{\mathrm{o}}{ }^{2}\right)^{2}\right]^{1 / 2}$ 
Table S2. Characteristic IR bands of the compounds $\mathbf{1}-\mathbf{3}\left(\mathrm{cm}^{-1}\right)$

\begin{tabular}{llll}
\hline Compound & Aromatic ring & $\mathrm{C}-\mathrm{N}$ & $\mathrm{C}-\mathrm{O}$ \\
\hline$\left[\mathrm{Ag}(\mu \text {-aca })\left(\mu_{4} \text {-bztpy }\right)\right]_{1 / 2}(\mathbf{1})$ & $1599 \mathrm{~s}, 1572 \mathrm{~m}, 1553 \mathrm{~s}$ & $1315 \mathrm{~m}, 1275 \mathrm{w}$ & $1553 \mathrm{~s}, 1382 \mathrm{w}$ \\
{$[\mathrm{Ag}(\mu$-bza $)(\mu$-bpa $)](\mathbf{2})$} & $1594 \mathrm{~s}, 1551 \mathrm{~s}$ & $1368 \mathrm{~s}$ & $1551 \mathrm{~s}, 1392 \mathrm{~m}$ \\
{$\left[\mathrm{Ag}_{2}(\mu \text {-aca })_{2}(\mu \text {-bpa })_{2}\right] \cdot$ EtOH$\cdot 2 \mathrm{H}_{2} \mathrm{O}(\mathbf{3})$} & $1594 \mathrm{~m}, 1551 \mathrm{~s}$ & $1318 \mathrm{~s}, 1273 \mathrm{~m}$ & $1551 \mathrm{~s}, 1392 \mathrm{~s}$ \\
\hline
\end{tabular}

Table S3. Absolute quantum yields for $\mathbf{1}-\mathbf{3}(\lambda \mathrm{ex}=390,394$, and $394 \mathrm{~nm}$, respectively).

\begin{tabular}{cccc}
\hline Compound & Quantum yield & Quantum yield & Quantum yield \\
\hline$\left[\mathrm{Ag}(\mu \text {-aca })\left(\mu_{4} \text {-bztpy }\right)\right]_{1 / 2}(\mathbf{1})$ & $9.80 \%$ & $9.54 \%$ & $9.75 \%$ \\
{$[\mathrm{Ag}(\mu$-bza $)(\mu$-bpa $)](2)$} & $14.50 \%$ & $14.30 \%$ & $13.64 \%$ \\
{$\left[\mathrm{Ag}_{2}(\mu \text {-aca })_{2}(\mu \text {-bpa })_{2}\right] \cdot \mathrm{EtOH} \cdot 2 \mathrm{H}_{2} \mathrm{O}(\mathbf{3})$} & $15.09 \%$ & $14.78 \%$ & $14.12 \%$ \\
\hline
\end{tabular}

